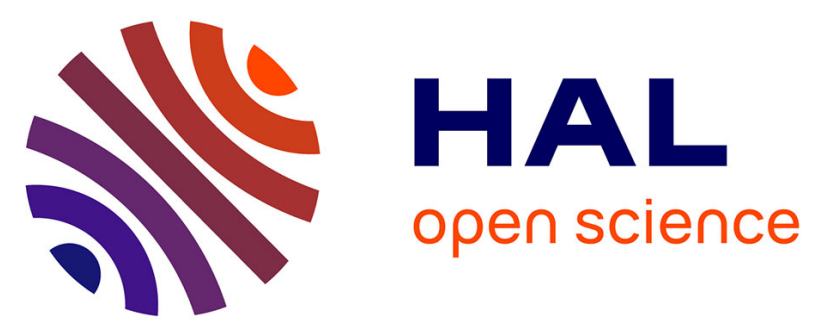

\title{
Improving biodiversity indicators of sustainable forest management: Tree genus abundance rather than tree genus richness and dominance for understory vegetation in French lowland oak hornbeam forests
}

\author{
S. Barbier, Richard Chevalier, P. Loussot, L. Bergès, Frédéric Gosselin
}

\section{To cite this version:}

S. Barbier, Richard Chevalier, P. Loussot, L. Bergès, Frédéric Gosselin. Improving biodiversity indicators of sustainable forest management: Tree genus abundance rather than tree genus richness and dominance for understory vegetation in French lowland oak hornbeam forests. Forest Ecology and Management, 2009, 258S (Supplement), p. S176 - p. S186. 10.1016/j.foreco.2009.09.004 . hal00455637

\author{
HAL Id: hal-00455637 \\ https://hal.science/hal-00455637
}

Submitted on 10 Feb 2010

HAL is a multi-disciplinary open access archive for the deposit and dissemination of scientific research documents, whether they are published or not. The documents may come from teaching and research institutions in France or abroad, or from public or private research centers.
L'archive ouverte pluridisciplinaire HAL, est destinée au dépôt et à la diffusion de documents scientifiques de niveau recherche, publiés ou non, émanant des établissements d'enseignement et de recherche français ou étrangers, des laboratoires publics ou privés. 
1 Improving biodiversity indicators of sustainable forest management: tree genus abundance

2 rather than tree genus richness and dominance for understory vegetation in French

3 lowland oak hornbeam forests

4

5 Stéphane Barbier $\S \perp$, Richard Chevalier§, Philippe Loussot $¥ \sqrt{ }$, Laurent Bergès $\S$, Frédéric

6 Gosselin§ (corresponding author)

7

8 § Cemagref, UR EFNO, Domaine des Barres, 45290 Nogent-sur-Vernisson, France

$9 \perp$ Current address: Conservatoire Botanique National, Domaine de Certes, 33980 Audenge,

10 France

$11 ¥$ Chambre d'Agriculture de Seine-et-Marne, 418 rue Aristide Briand, 77350 Le Mée sur Seine,

12 France

$13 \sqrt{ }$ Current address: Enviro Conseil Travaux, 77230 Villeneuve-sous-Dammartin, France

15 Corresponding author: Frédéric Gosselin

16 Cemagref, UR EFNO, Domaine des Barres, 45290 Nogent-sur-Vernisson, France

17 E-mail: frederic.gosselin@cemagref.fr

18 Telephone number: +33238950358

19 Fax number: +33238950359

20 Supplement, pp. S176-S186

(doi: 10.1016/j.foreco.2009.09.004). Available at http://dx.doi.org/10.1016/j.foreco.2009.09.004 
Abstract

Two different biodiversity indicators based on tree species diversity are being used, in

30 Europe and France respectively, without strong prior scientific validation: (1) tree species or

31 genus richness as a positive indicator, and (2) relative abundance of the main species

32 ("dominance") as a negative indicator. We tested the relevance of these ecological models as

33 indicators of understory vegetation biodiversity in sustainable forest management by comparing

34 them to other ecological models, mainly related to tree species composition and abundance. We

35 have developed Bayesian statistical models for richness and abundance of ecological groups of

36 understory vegetation species, classified according to successional status or shade tolerance. The

37 count data probability distributions in the models were new to ecology. These models were fitted

38 using data from 49 plots in mature lowland forests in the centre of France (Bassin Parisien) with

39 similar site conditions. We used equivalence and inequivalence tests to detect negligible and non-

40 negligible effects.

41 Tree genus richness and dominance resulted in models that were worse than ones based

42 on the abundance of tree genus groups. Furthermore, the only significant results for dominance

43 and tree genus richness were opposite to the ones implicitly assumed in the indicator system.

44 However, the magnitude of the effects and which indicator provided the best statistical model

45 varied among ecological groups of plants. Our results show the negative non-negligible effect of

46 the basal area of undergrowth tree species on the cover of all ecological groups of herbaceous and

47 woody species, and on the species richness of non-forest and peri-forest herbaceous and woody

48 species. Compared to the literature, our sampling design strongly controlled forest and site type,

49 thus removing to some degree the potential confusion between influences on biodiversity of

50 management specific variables and other ecological variables. We discuss our results from both

51 an ecological perspective and in terms of the value of these groups as indicators of sustainable 
52 management. For example, the best-performing model was a multivariate model, which may be

53 more difficult to explain to forest managers or policy-makers than an indicator simply based on 54 tree genus richness.

55

\section{Key-words}

57 Deciduous forest; temperate forest; tree species; Bayesian count models; model comparison;

58 ordered categorical data; equivalence tests; Quercus. 


\section{Introduction}

61 Improving biodiversity is one of the main objectives of the international Convention on

62 Biological Diversity and associated National Strategies. Part of these strategies are sectorial, i.e.

63 they try to improve biodiversity assessment in each major domain of human activity. Forestry

64 and forests are no exceptions. As a result, biodiversity has been identified as one of the six

65 criteria of sustainable forest management in Europe (MCPFE, 2003). A dozen or so indicators for

66 biodiversity have been defined, that partly vary among countries. By indicator, we mean any

67 measurable correlate to the particular aspects of biodiversity being studied (Duelli and Obrist,

68 2003). Yet, these indicators have not been defined thoroughly, since the information to interpret

69 them as pressures on biodiversity is often lacking - e.g. what components of biodiversity do they

70 indicate? What are the magnitude and direction of the relationship between indicator and

71 biodiversity? In which ecological conditions is this relationship valid? (Lindenmayer et al., 2000,

72 Duelli and Obrist, 2003). What's more, there have been few efforts to compare existing indicators

73 with new, potentially more appropriate ones.

74 One of the main acts in forest management is the selection of tree species. Tree species

75 identity, abundance and diversity can shape the mean level of resources available to understory

76 vegetation as well as their spatial variation, and thus can influence understory diversity and

77 abundance (Barbier et al., 2008, Mölder et al., 2008, Barbier et al., In Press). This may explain

78 why tree species richness and dominance are used as indicators of biodiversity in Europe and

79 France (MCPFE, 2003, Ministère de l'Agriculture et de la Pêche, 2006). Yet, the state of the

80 literature seems to question this choice if tree species richness and dominance are used in

81 sustainable management practices as indicators of larger components of biodiversity, here:

82 understory vegetation diversity - i.e. the diversity of vascular plants and bryophytes growing on 
83 the forest floor below $2 \mathrm{~m}$. Indeed, when summarizing a series of results, Glenn Lewin (1977, p.

84 158) stated that "relationships between [the diversity of] strata that do occur appear to be the result of local moisture gradients and substrate types". Actually, most of the work that has focused on dominant tree species identity or tree species diversity as indicators of understory diversity (cf. references quoted in the Discussion) was based on sampling schemes that included a substantial variation in site type conditions. This is reflected in some of the results, e.g. those in Mölder et al. (2008) where understory species richness was strongly related both to tree species richness and soil $\mathrm{pH}$. In such conditions, these indicators - which may be more related to site type variations than to forest management (cf. Lindenmayer, 1999 and Gilliam, 2007 for similar examples) - may not qualify as valid biodiversity indicators of sustainable forest management.

The aim of this study was to test and compare the relevance of different ecological models related to tree species diversity and abundance as indicators of sustainable management for understory vegetation biodiversity variation. By ecological models, we mean the identity of the particular ecological factors that are included in a statistical model using floristic biodiversity as the response variable. Our general approach was to compare potential indicators based on ecological models involving tree species richness, abundance and composition, among themselves and with other potential indicators (e.g. humus type, date and site chemical characteristics). We defined these ecological models (cf. Tables $1 \&$ 2) from those currently being used in sustainable management evaluations but also from those found in past studies. Most of these models involve variables that can be quantified based on dendrometric data such as those from the French Forest National Inventory (e.g. in terms of scale).

We first focused our attention on ecological models related to tree genus composition and abundance, partly corresponding to the domain covered by indicator 4.1 in Ministère de l'Agriculture et de la Pêche (2006). Our first model related to tree species was the (dominant) 
107 Tree genus Group Identity (hereafter called TGI). TGI is not as such an indicator of forest

108 biodiversity in Europe and France, although it is part of indicator 4.1.1 in France and is

109 considered to be an indicator of forest resources - $\mathrm{n}^{\circ}$ 1.1.4 (cf. MCPFE, 2003, Ministère de

110 l'Agriculture et de la Pêche, 2006). Our second model related to the tree layer was total Tree

111 Abundance, here basal area (hereafter called $T A$ ). A mix of $T G I$ with $T A$ - here interpreted as an

112 additive effect of both factors: $T G I+T A$ - is used in France as an indicator of biodiversity

113 (Ministère de l'Agriculture et de la Pêche, 2006): it was our third model. Since much of the

114 existing literature reports the effect of the abundance of particular tree species on floristic

115 biodiversity, we constructed our fourth model on the absolute abundance of different tree genus

116 groups, as did Korb et al. (2007), here with a grouping based on Successional/Structural status

117 (model called TGAS, much as in Auclair and Goff, 1971). Here we distinguished Pioneer tree

118 genera from ordinary Post-Pioneer tree genera, including oaks, and from Post-Pioneer tree genera

119 that form dense undergrowth in deciduous French forests and have a higher tolerance to shade

120 than other trees (Carpinus betulus and Tilia sp.; Rameau et al., 1989, Vera, 2000, but see

121 Evstigneev, 1988 for hornbeam). Following Rice et al. (1984), Betts et al. (2005) and Barbier et

122 al. (2008), we preferred to use absolute rather than relative abundance of groups of trees because

123 (i) we assume that this value can lead to different management implications than those based on

124 the relative abundance of trees; and (ii) we hypothesize that this value is more related to the effect

125 of the tree canopy on ecological gradients such as light (e.g. Sonohat et al., 2004). Many different

126 mechanisms can account for the effects of TGI and various measures of tree abundance on

127 floristic biodiversity, such as differences in light, water and nutrients, or physical effects of the

128 humus layer (cf. Michalet et al., 2002, Gilliam, 2007, Barbier et al., 2008). Other ecological models based on tree species involve the notion of species diversity of

130 the tree stand, with the underlying assumption that a more diverse tree stand might indicate more 
131 diverse understory vegetation. We have retained as our fifth and sixth models the indicators used

132 in France, i.e. Tree Genus Dominance (TGD in the model TGI+TGD; Ministère de l'Agriculture

133 et de la Pêche, 2006) and Tree Genus Richness (TGR). Tree genus Dominance (TGD) was

134 calculated as the maximum among the tree genera of their relative basal area in the plot, and Tree

135 Genus Richness (TGR) was calculated as the genus richness of living trees and shrubs collected

136 from the dendrometric relevé, including all woody material with diameter at breast height (DBH)

$137>2.5 \mathrm{~cm}$. More precisely, model mTGR4 - the minimum between Tree Genus Richness and $4-$

138 is indicator $\mathrm{n}^{\circ} 4.1$ in Ministère de l'Agriculture et de la Pêche (2006). Herein, we considered both

$139 m T G R 4$ - our seventh model - and TGR, which varied between 1 and 8, with a mean of 4.3 (cf.

140 Table 2). At least two mechanisms could explain the positive effect of tree species diversity on

141 understory diversity: either the higher heterogeneity of resource levels under diverse tree stands

142 (Brewer, 1980, Barbier, 2007, Mölder et al., 2008) or a common response of the richness of these

143 two strata to the same environmental factors (cf. Glenn Lewin, 1977, Gilliam, 2007, Mölder et

144 al., 2008).

145 Finally, we also included three models that are not linked to the tree layer, but which

146 could account for potential biases in our sampling scheme. These were our three final non-null

147 models:

$148-$ a model Date including the date of the floristic relevé;

$149-$ a model called Block, that incorporated the identity of the forest Block, distinguishing

150 the Southern Block - corresponding to the Villefermoy forest - from the Northern Block;

$151-$ a model called Soil that included variables associated to site type - here two chemical

152 properties of the organic-mineral layer, humus type and depth of dominant clay content (cf. Table $1532)$. 
In this study, our first methodological choice was to test the relevance of these ecological

155 models irrespective of site type variation (cf. above). We therefore decided to control site type as 156 much as possible, in order to compare varying tree species identities, diversities and abundances

157 on a similar site type. We did this by locating our study plots in a limited geographical area with

158 the same climatic characteristics, by a priori controlling for site type when choosing forest plots,

159 and by a posteriori quantifications of soil properties known to be relatively constant during the

160 forest cycle, such as $\mathrm{pH}$ of the first mineral layer.

161 Our second methodological choice was to analyze vegetation diversity not as a whole but in

162 separate ecological groups, which are known to have different ecological requirements (Gosselin

163 and Gosselin, 2004). We assumed that model relevance, and direction and magnitude of effect

164 within one model, would vary according to the understory ecological group considered.

165 Discrepancies or lack of correlation between total species richness and the diversity of particular 166 ecological or functional groups were indeed frequent (Lindenmayer, 1999, Duelli and Obrist,

167 2003). We therefore analyzed the understory abundance - here, percent cover - and species

168 richness of ecological groups associated with the successional status, light requirements and life

169 form of species. The use of the successional status of plants - or their association to particular

170 phytosociological groups - is rather frequent in the forest ecology literature, either directly in the

171 analyses (e.g. Kwiatkowska, 1994; Kwiatkowska et al., 1997; ; Spyreas and Matthews, 2006) or

172 more indirectly, by restricting the analysis of vegetation to "forest" species only (Van Oijen et al.,

173 2005), or in interpretations of the variations of total species richness (Mölder et al., 2008). Light

174 preference was chosen because we assumed that light could be an important mechanism in

175 explaining floristic diversity response to tree species identity or abundance.

176 Finally, we analyzed the data in a quantitative manner through the use of Bayesian parametric 177 statistical models, based on improved probability distributions. For the analysis of the results, we 
178 coupled the model comparison framework (Hilborn and Mangel, 1997; Spiegelhalter et al., 2002)

179 with the analysis of the non-negligibility of the effects (Dixon and Pechmann, 2005). Among the 180 ecological models analysed, this helped us distinguish those which incorporated a negligible

181 effect from the ones where data were insufficient to discriminate between negligible and non182 negligible effects.

183 As will be seen in the discussion, the study of the relationship between tree species and 184 understory biodiversity is not new - and approaches are quite diverse. This is why we have 185 adopted a pluralistic view of this relationship, without one preferred ecological model or 186 hypothesis, that comes close to the multiple hypotheses framework of Chamberlin (1965; cf. also 187 Hilborn and Mangel, 1997). Indeed, our aim was to find the best ecological models of 188 biodiversity variation among the biodiversity indicators currently being used in France and the 189 ecological models found in the literature, and to identify cases where the effects were non190 negligible.

192 Material and methods

\section{Study area}

194 The study area encompassed ca 8,000 ha in two zones included in a large area about $50 \mathrm{~km}$ 195 east and south-east of Paris, France, in the region called "Brie Francilienne", in the Seine et 196 Marne administrative department. The forests studied ranged from $48^{\circ} 27^{\prime} \mathrm{N}$ to $48^{\circ} 51^{\prime} \mathrm{N}$ and from $1972^{\circ} 39^{\prime} \mathrm{W}$ to $2^{\circ} 57^{\prime} \mathrm{W}$ and were located on a plateau between 100 and $140 \mathrm{~m}$ above sea level. We 198 focused on four different forests called Ferrières, Armainvilliers, Crécy, and Villefermoy - the 199 latter was about $50 \mathrm{~km}$ south of the three others, which were relatively contiguous. This region 200 had an oceanic-subcontinental climate characterized by a mean annual temperature of $10.6^{\circ} \mathrm{C}$ and 201 a mean annual precipitation of about $660 \mathrm{~mm}$ (Météo France, 1996). In the plots studied, the soil 
was composed of a layer of silt around $45 \mathrm{~cm}$ in depth above a clay layer. The substratum was

203 limestone from the Oligocene (Ferrières, Armainvilliers, and Crecy) and the Cretaceous period

204 (Villefermoy). The soil was brown-leached, with moderate discoloration due to waterlogging,

205 with more intensive discoloration at a depth of around $20 \mathrm{~cm}$. The soil was mildly acidic, with a

206 neutroclinous to acidiclinous vegetation. The mean value of the $\mathrm{pH} \mathrm{KCl}$ in the first mineral layer

207 was 3.8 (Table 2). Layers with dominant clay texture appeared at an average depth of $46 \mathrm{~cm}$ in

208 the plots studied (Table 2). All the plots were at least $50 \mathrm{~m}$ from the forest edge, to avoid

209 interfering edge effects.

210 The forests we studied are almost exclusively composed of deciduous trees, mainly oaks

211 (Quercus petraea and Q. robur) and hornbeam (Carpinus betulus), though other tree species such

212 as lime (mainly Tilia cordata), birch (mainly Betula pendula) and aspen (Populus tremula and P.

213 canescens) may be locally dominant or co-dominant. Sweet chestnut (Castanea sativa) was also

214 frequent. Hardwood management in the area consisted in the conversion of old coppice-with-

215 standards stands to even-aged oak high forests. Some of the stands, however, were being

216 managed as uneven-aged oak high forests.

218 Data collection

219 Forty-nine plots were selected for (i) a common forest site type, described above; and (ii)

220 their inclusion in 9 forest stand types defined by oak age structure and tree species composition -

221 three types corresponded to mixed hardwood stands with uneven-aged oak, four types to oak-

222 hornbeam or pure oak stands with even-aged oak, and three types dominated either by hornbeam,

223 lime or pioneer tree species. Because much of the existing literature concerns only mature stands,

224 and due to results that indicate that tree species composition is well correlated with understory 
biodiversity only in "mature" forest stands (Gilliam et al., 1995), we excluded young stands from our study, i.e. we did not consider stands at regeneration, seedling or thicket stages.

In each 20x20m square plot, vegetation was inventoried for 85 minutes once in May, June or early July, 1999, by one of two botanists.

Vascular plants and bryophytes were recorded only if they were rooted in the litter and soil, not if they were growing on woody and rocky substrates. We considered vegetation below $2 \mathrm{~m}$ in height. Botanical nomenclature followed Kerguélen (1999) for vascular plants, Corley et al. (1981) and Corley and Crundwell (1991) for mosses and Grolle (1983) for hepatics.

Identifications were made visually in the field, at the species level whenever possible. However, some species aggregates were defined because of identification problems (Agrostis canina $+A$. stolonifera, Eurhynchium stokesii + E. praelongum, Juncus effusus + J. conglomeratus, Luzula multiflora + L. forsteri, Lythrum salicaria + Epilobium tetragonum + Hypericum tetrapterum, Populus tremula + P. canescens, Salix cinerea + S. aurita, Viola reichenbachiana $+V$. riviniana). Six species were identified in the field as different from the others but they could not be named. Some taxa were determined only at the genus level (Abies sp., Calypogeia sp., Fissidens sp., Isothecium sp., Lophocolea sp., Plagiothecium sp., Trifolium sp.). However, we have used the term "species richness" for what was actually taxon richness.

For each species present in a relevé, we coded the estimated abundance-dominance of the species in each of the following strata: $<0.5 \mathrm{~m} ; \geq 0.5$ and $<2 \mathrm{~m}$, and in each of the four square $100 \mathrm{~m}^{2}$ supblots in the a $20 \times 20 \mathrm{~m}$ square plot. Our data consisted in the mean over the plot of the sum of the cover of each species in these two strata in each subplot. The abundance-dominance of each species in each strata was rated using the Braun-Blanquet phytosociological classes. The cover of an individual reaching a given stratum was totally attributed to that stratum. These Braun-Blanquet classes were then transformed into numbers, according to one of the codings in 
van der Maarel (1979) for classes 2 to 5, and according to calibrations we made between total

250 estimated cover and the number of species in the classes $i,+$ and 1 , and the predicted cover in the 251 four last classes ( 2 to 5 ). With this calibration, i became $0.05 \%$; + became $1 \%$ for non bryophytes 252 and $0.15 \%$ for bryophytes; 1 became $2.75 \%$ for non bryophytes and $1.15 \%$ for bryophytes ; 2,3 , 2534 and 5 became $17.5 \%, 37.5 \%, 62.5 \%$ and $87.5 \%$, respectively.

254 In each plot, tree basal area at breast height ("G", in $\mathrm{m}^{2} \cdot \mathrm{ha}^{-1}$ ) was calculated species by 255 species, in three different configurations: 1) four circles with $4 \mathrm{~m}$ radius at the center of each 256 subplot for trees with $2.5 \mathrm{~cm}<$ diameter at breast height $(\mathrm{DBH})<7.5 \mathrm{~cm} ; 2)$ the four square 100 $257 \mathrm{~m}^{2}$ subplots for $7.5 \mathrm{~cm}$ to $17.5 \mathrm{~cm} \mathrm{DBH}$; and 3) the $22 \mathrm{~m}$ radius circle at the center of the plot for 258 trees with DBH $>17.5 \mathrm{~cm}$. Specific parameters in the models were calculated from this

259 dendrometric inventory (Table 2). Some shrubs were included in the dendrometric relevé; in our 260 case, they however had a minor contribution to both basal area and "tree" genus richness data 261 (mean richness of shrubs: 0.27 compared to a mean TGR of 4.6; cf. Table 2).

262 At each of the four $100 \mathrm{~m}^{2}$ subplots, a probe was used to measure the depth to which clay was 263 dominant. The four values were averaged for each sampling plot. At each of the four $100 \mathrm{~m}^{2}$ 264 subplots a soil sample was taken at $5-10 \mathrm{~cm}$, corresponding to the first organic-mineral layer (A 265 layer), and then at $15-25 \mathrm{~cm}$, corresponding to the first mineral layer (B layer). The four samples 266 of the same layer were combined, then air-dried and sieved at $2 \mathrm{~mm}$ for laboratory analyses: $267 \mathrm{pH} \mathrm{KCl}$, total nitrogen $(\mathrm{N})$ and organic carbon (C). Analytical methods followed ISO standards 268 (anonymous, 1999).

269 The humus form was visually assessed in each plot, based on Brêthes et al. (1995), modified 270 by Jabiol et al. (2000). Humus Index was then calculated as in Ponge et al. (2002). 


\section{Data analysis}

273 In our analyses we focused on two ecological characteristics of understory species and their

274 life traits to define ecological groups: light preference and successional status, crossed with life 275 form.

276 For light preference ("HELIO" classification), we distinguished three species classes 277 according to light Ellenberg indicator values, "L" (Ellenberg et al., 1992): heliophilous (L $\geq 7$, 278 "helio"), intermediate-light ( $\leq \leq \mathrm{L}<7$, "mid"), and shade-tolerant species ( $<<5$, "shad"). Species 279 without an L value were classified according to Rameau et al. (1989) and our own knowledge. 280 For successional status of species ("SUCC" classification), we distinguished three classes: non 281 forest species ("NF") whose habitats are not linked to forests, peri-forest species ("PF") whose 282 habitats are found close to mature forests either temporally (in the early stages of succession) or 283 spatially (along edges), and mature forest species ("AF") that reach their maximum abundance in 284 mature forests. For this classification, we followed Julve (2002), Hodgson et al. (1995) and 285 Rameau et al. (1989). These two classifications - HELIO and SUCC - were distinguished in each 286 of the following life form groups: bryophytes, herbaceous (i.e. non woody vascular) plants and 287 woody species. The latter distinction is frequent in the literature (e.g. Glenn-Lewin, 1977). Only 288 groups which were represented by at least one species in more than 20 plots and more than 60 289 subplots were taken into account in the analysis.

We analyzed the effect of our different ecological models on the species richness and cover of 292 the understory species groups defined above, at the $400 \mathrm{~m}^{2}$ scale. The effects of the model were: 293 the intercept, the observer effect, and the parameters of the ecological model (cf. Table 1). We analyzed all the ecological groups of a given classification in the same statistical model, with 
different estimated parameters for each group - except for the qualitative observer effects that were shared between ecological groups.

For species richness, the models were mostly equivalent to Poissonian generalized linear models, except that the Poisson distribution was replaced by a more flexible distribution - the Bernoulli/Double Polya mixture-Poisson-Negative Binomial family - allowing both under- and over- dispersion (Gosselin, Submitted a). This continuum of distributions uses different distributions according to an estimated dispersion parameter $\sigma$ for each ecological group: if greater than 1.0, we use a negative binomial distribution, if equal to 1.0, we use the Poisson distribution, and if less than 1.0, the Bernoulli/double Polya mixture distribution parameterized so that the expected index of dispersion is asymptotically $\sigma$ (cf. Gosselin, Submitted a). The link function was the logarithm.

Cover of the ecological groups was analyzed with the same framework, except that the underlying probability distribution was not a count data distribution but a cumulative logit distribution (Liu and Agresti, 2005). We distinguished five intervals of cover $(0 ;] 0 ; 1]] 1 ; 5$,$] ,$ ] $5 ; 25]] ,25 ; \infty[$ ) and applied the cumulative logit through equations of the shape:

$P\left(Y>\alpha_{i} \mid \gamma\right)=\frac{1}{1+\exp \left(\beta_{i}\right) / \gamma}$

where $Y$ is the cover value, $\gamma$ is the positive quantity that incorporates the fixed effects through an exponential function, $\left\{\alpha_{1}, \alpha_{2}, \alpha_{3}, \alpha_{4}\right\}=\{0 ; 1 ; 5 ; 25\}$ and $\beta_{1}<\beta_{2}<\beta_{3}<\beta_{4}$. This distribution has the characteristic that the odds values of the cumulative probabilities $P\left(Y>\alpha_{i} \mid \gamma\right)$ are equal to $\gamma$, and in particular do not depend on the cover class $i$. We used this distribution because we did not find any better alternative to model values that could be either null or positive and 
simultaneously continuous. Our highest cut point, $\alpha_{4}=25$, was such that less than $5 \%$ of the

317 data were above it.

318 In our Bayesian models, the priors of fixed effects were mostly weakly informative: the prior

319 for fixed effects was a centered normal distribution with a standard deviation 3 times the inverse

320 of the standard deviation of the associated ecological parameter. The priors for the other

321 parameters - the dispersion parameter and the $\beta_{i}$ for the cover models - were also chosen mostly

322 non informative.

323 The Bayesian models were fitted through the adaptive MCMC described in Roberts and

324 Rosenthal (In Press), based on three trajectories of 20,000 iterations, a burning period of 7,000

325 iterations and a thinning parameter of 10 . The convergence of the models was checked with the

326 Rubin and Gelman Rhat quantity (Gelman et al., 2004), smaller than 1.1. The adequacy of the

327 probability distributions with the data was qualified through sampled posterior predictive values

328 (Johnson, 2007, Gosselin, Submitted b).

329 To compare our models one with each other, we used the DIC - Deviance Information

330 Criterion (Spiegelhalter et al., 2002) -, which is the most common information criterion to

331 compare models in a Bayesian setting. The smaller the DIC, the better the model.

332 The sign and magnitude of the effects of parameters in the ecological model were analyzed

333 for the SUCC classification and for models used in current indicators (TGR, mTGR4, TA in

334 TGI+TA and TGD in TI+TGD) as well as for the model that turned out to be the best (TGAS).

335 For each parameter in these models we reported the multiplicative coefficient - of the mean fitted

336 value for species richness and of the odds of cumulative probabilities $P\left(Y>\alpha_{i}\right)$ for abundance

337 data - associated with an increase of the ecological parameter of around one standard deviation,

338 i.e. $5 \mathrm{~m}^{2} \cdot \mathrm{ha}^{-1}$ for basal area parameters, 1.5 genera for genus richness and 0.2 for tree genus 
339 dominance. For each parameter we reported the mean value of the multiplier, its $95 \%$ confidence

340 interval, and the probability of the significance test that the parameter was null. Levels of

341 statistical significance for parameters were symbolized as follows: $* * *=p<0.001, * *=p<0.01, *$

$342=\mathrm{p}<0.05$. Inspired from Dixon and Pechmann (2005), we also did an analysis based on

343 equivalence and inequivalence tests to detect negligible effects: based on Bayesian parameter

344 estimation as in Camp et al. (2008), the aim of the analysis was to identify when the parameter

345 has a high probability of being in an interval, called the negligible interval, that is a priori

346 considered to be representing negligible effects, when the parameter had a high probability of

347 being below this interval and when the parameter had a high probability of being above. We also

348 distinguished two negligible intervals: one for weak negligibility and one for strong negligibility.

349 Denoting by $\beta$ one value of the multiplier stemming from the posterior distribution of the

350 Bayesian model, and by $0<b_{1}<b_{2}$ the levels associated to the two negligible intervals, we

351 therefore used the symbol 0 to describes cases where $\mathrm{P}\left(-b_{2}<\log (\beta)<b_{2}\right) \geq 0.95$ and 00 for the

352 more stringent: $\mathrm{P}\left(-b_{1}<\log (\beta)<b_{1}\right) \geq 0.95$. Similarly, we denoted by "-" cases where

$353 \mathrm{P}\left(\log (\beta)<-b_{1}\right) \geq 0.95$ and "--" cases where $\mathrm{P}\left(\log (\beta)<-b_{2}\right) \geq 0.95$. These cases correspond to

354 non-negligible negative and strongly non-negligible negative effects, respectively. We had

355 similar notations - "+" and "++" - for the positive side. We chose $b_{1}=0.1$, and $b_{2}=0.2$ for

356 species richness data, corresponding respectively to a multiplication of species richness by

$357 \exp (0.1) \approx 1.11$ and $\exp (0.2) \approx 1.22$ at the upper side of the negligible interval. For abundance

358 data, we used $b_{1}=0.25$, and $b_{2}=0.5$, corresponding to divisions by $\exp (0.25) \approx 1.28$ and

$359 \exp (0.5) \approx 1.65$ of the odds value of the cumulative probabilities $P\left(Y>\alpha_{i}\right)$. For example, using 
$b_{2}=0.5$, an initial value of $P\left(Y>\alpha_{i}\right)=0.5$ (respectively $P\left(Y>\alpha_{i}\right)=0.1$ ) would be

361 transformed to $P\left(Y>\alpha_{i}\right)=0.38$ (respectively $P\left(Y>\alpha_{i}\right)=0.06$ ).

\section{Results}

364 The most frequent understory species - found in more than half of the plots - were Rubus

365 fruticosus, Carpinus betulus, Quercus robur, Lonicera periclymemum, Populus tremula* Populus

366 canescens, Tilia cordata, Castanea sativa, Fraxinus excelsior for woody species, Carex

367 pilulifera, Convallaria majalis, Dryopteris carthusiana, Dryopetris filix-mas and Luzula pilosa

368 for herbaceous species, and Atrichum undulatum, Dicranella heteromalla, Eurhynchium striatum,

369 Eurhynchium stokesii, Hypnum cupressiforme, Polytricum formusum and Thuidium tamariscium

370 for bryophyte species. Mean plot richness levels were $10.1( \pm 1.8)$ for bryophytes, $9.1( \pm 7.0)$ for

371 herbaceous species and $9.3( \pm 3.2)$ for woody species.

372 The Bayesian models converged correctly according to the Rubin and Gelman Rhat quantity

373 and the goodness of fit diagnostics did not show significant departures from the uniform

374 distribution, except for intermediate light bryophyte and shade-tolerant herbaceous species

375 abundance. Observer effects were significant and rather strong for abundance data and

376 insignificant for species richness data. For species richness data for bryophyte and woody species

377 groups, dispersion parameters were below 1 - indicating underdispersion relative to the Poisson

378 distribution; they were mostly above 1 for herbaceous species groups - except for AF herbaceous

379 species (results not shown).

380 Overall, the best ecological models in terms of DIC were models including one form of tree

381 abundance and tree genus identity (TGAS, TGI+TA for abundance data; Tables 3 to $4 \&$ S1 \&

382 S2). Models associated to tree genus richness were less effective than these best models by more 
383 than 5 DIC units - except for intermediate light bryophytes -, and often came close to the null

384 model by less than 5 DIC units. This was also the case for the models including the effect of Date 385 of sampling and the forest Block (models "Date" and "Block"). Models associated to tree genus 386 dominance (TGI+TGD) were also less effective than the best models by more than 5 DIC units 387 (except for shade-tolerant and AF herbaceous species richness and abundance, AF and shade388 tolerant woody species richness, and AF bryophyte and intermediate light woody species 389 abundance). They also came close to their baseline reference (TGI) by less than 5 DIC units in 390 half of the cases for abundance data and in all cases for species richness data, with only one 391 exception: intermediate light herbaceous species. The model with site effects fell in the middle 392 and was much better than the null model for most groups. It was even the best model for some 393 groups. The identity of the best model varied slightly according to the ecological group 394 considered (Tables 3, 4, S1 \& S2). TGAS was the best model or very close to the best model (less 395 than 2 DIC units) for all the ecological groups with the following exceptions: AF and 396 intermediate light bryophyte species richness, and shade-tolerant herbaceous species abundance. 397 The best model was at more than 5 DIC units from the null model except for the abundance of 398 intermediate light bryophytes.

399 The analysis of the magnitude and "non-negligibility" of the effects for the SUCC 400 classification (Tables 5 and 6) produced the following results. The analyses for the basal area of 401 Pioneer species (G.Pi) and of Post-Pioneer species including oaks (G.Qu) and Tree Genus 402 Richness (TGR) were negligible (except for NF and PF herbaceous species, and AF herbaceous 403 species only for G.Pi) for species richness data. For abundance data, the results were without 404 information related to negligibility (except for AF bryophytes where the effect was negligible for 405 TGR). This was not the case for the basal area of undergrowth tree species (G.Un) which 406 included non-negligibly negative effects for all the ecological groups (except for AF woody 
species richness and AF bryophytes for which the effect was negligible, and species richness of

408 AF herbaceous species for which the negligibility of the effect could not be determined).

409 Somewhat similar results were found for total basal area in the model TGI+TA. For the restricted

410 Tree Genus richness (mTGR4) and tree genus dominance (TGD) the effects were without

411 information relative to negligibility, except for AF bryophyte and woody species richness for

412 mTGR4 (negligible effect) and NF herbaceous and AF woody species abundance (non-negligible

413 negative for mTGR4, and non-negligible positive for TGD).

414 The negligible and non-negligible ecological effects of the Soil model (Tables S3 \& S4)

415 were:

$416-$ negligible effects of ClayDepth on all non-herbaceous species groups for species richness;

417 of HUMUS, $\mathrm{pH}$ and $\mathrm{C} / \mathrm{N}$ on $\mathrm{AF}$ bryophyte species richness; of $\mathrm{C} / \mathrm{N}$ on $\mathrm{AF}$ herbaceous and $\mathrm{AF}$

418 and PF woody species richness;

$419-$ non-negligible negative effects of HUMUS and $\mathrm{pH}$ on PF and NF groups species richness, 420 on $\mathrm{AF}$ and NF herbaceous species abundance; non-negligible negative effects of $\mathrm{pH}$ on the 421 abundance of PF herbaceous and AF woody species.

\section{Discussion}

\section{Towards better indicator(s) of understory diversity and abundance}

Our results show that the currently preferred indicators of biodiversity - restricted tree 426 genus richness (mTGR4) and tree genus dominance (TGD) (Ministère de l'Agriculture et de la

427 Pêche, 2006) - are not among the best models for the ecological groups studied and generally do 428 not show significant effects on biodiversity. However, our data did not give any information on 429 negligibility, except for mature forest (AF) bryophyte and woody species richness for dominance, 430 for which the effect was negligible, and for the abundance data of non-forest herbaceous (NF 
431 herbaceous species) and AF woody species, which displayed a surprising significant, non-

432 negligible behavior: a decrease (respectively increase) in abundance of these groups with the

433 increase in restricted tree genus richness (resp. dominance). These surprising results might be

434 associated with significant correlations of mTGR4 and TGD with the basal area of undergrowth

435 trees (G.Un), respectively positive $\left(\rho=0.35^{*}\right)$ and negative $\left(\rho=-0.54^{* * *}\right)$. Thus, these tree

436 diversity indicators do not appear to be completely substantiated by our analyses, with two

437 ecological groups actually showing reverse trends compared to what is generally expected.

438 We must insist that many other references in the literature found positive effects of tree

439 species richness on understory biodiversity. Fourteen of the 36 correlations between TSR and

440 understory species richness or diversity we found in the literature (e.g. Daubenmire and

441 Daubenmire, 1968, Glenn-Lewin, 1977, p.159, references in Barbier et al., 2008, p.5, Mölder et

442 al., 2008) were positive and significant at the 5\% level; the mean coefficient of correlation was

4430.25 . However, these results may be more related to site type variations than to management

444 practices (cf. Glenn Lewin 1977, and Introduction section). Our results do not have this drawback

445 since site type was carefully controlled, at least in terms of soil acidity (cf. Table 2); site type

446 variations should be less likely to explain observed relationship between over- and understory in 447 our study than in other studies.

$448 \quad$ Models involving (dominant) Tree Genus Identity (TGI) were better models of biodiversity

449 variations than null models or models based on Tree Genus Richness (Tables 1 and 2). This

450 recalls the old forest ecology topic of biodiversity differences among dominant tree species

451 (Whittaker, 1956, Michalet et al., 2002, Barbier et al., 2008). Actually, the absence of strong

452 correlations between canopy tree species and understory species (Whittaker, 1956, Daubenmire

453 and Daubenmire, 1968) has been one of the arguments used to promote the ecological concepts 
454 of a loose organization of communities and the individualistic behavior of species assemblages

455 (Gleason, 1926). Yet, these analyses "appear to assume that interactions among species should be 456 similar at all points along environmental axes and that groups of species should be associated at 457 all points on a gradient if interdependence is to be accepted. However, virtually all types of 458 ecological interactions have been shown to vary with changes in the abiotic environment, and a number of field experiments indicate that positive effects become stronger as abiotic stress

460 increases" (Callaway, 1997). Interactions among plants have been shown to shift from 461 competition to facilitation along environmental gradients, with stronger positive interactions in 462 stressful abiotic conditions (Callaway, 1997, Michalet et al., 2002, Callaway et al., 2002). Also, 463 some papers have noted differences in the floristic species composition under different dominant 464 tree species; this difference tends to be strongest in specific site type conditions, especially in dry 465 conditions, and may even occur between two tree species assumed to be in the same ecological 466 group - Abies alba and Picea abies (Michalet et al., 2002). Other papers - reviewed in Barbier et 467 al. (2008) - have stressed that the local species richness was lower in stands dominated by 468 coniferous species than in stands dominated by hardwoods. Many different mechanisms can 469 account for such an effect (cf. Michalet et al., 2002, Barbier et al., 2008).

470 Other ecological models based on tree genus composition explained much better the diversity 471 variations for nearly all the ecological groups analyzed than the ones related to tree genus 472 diversity. These were the models accounting for the abundance of tree genus groups (TGAS) and, 473 for cover data, the model mixing dominant tree genus identity and total basal area (TGI+TA). We 474 found similar results when distinguishing tree species according to the richness of their leaf litter 475 (model TGAR, based on Aubert et al., 2004; Van Oijen et al., 2005; results not shown), which 476 gave a tree grouping very close to the successional grouping used in TGAS. The results of these 477 models are in agreement with other results in the literature showing the strong, negative effect of 
478 the abundance of one or several undergrowth tree or shrub species on vascular understory

479 biodiversity (Kwiatkowska, 1994; Kwiatkowska et al., 1997 for Carpinus betulus, Baker and van 480 Lear, 1998 for Rhododendron maximum, Ammer \& Stimm 1996 in Ewald, 2002 for Acer

481 pseudoplatanus, Brewer, 1980 for Acer saccharum and Fagus americana; see also Barbier et al., 482 2008, p. 5, and Rogers et al., 2008; but see Van Oijen et al., 2005 for a positive effect of such tree 483 species). Kwiatkowska et al. $(1994,1997)$ described the decline in the diversity of all understory 484 species groups with the increasing abundance of Carpinus betulus. This corresponds to the 485 transition phase of succession described in e.g. Spies (1997), where the dominance of the initial 486 tree species declines in favor of newly established tree species, a process also called 487 "mesification" (Rogers et al., 2008). We also found a negative effect of the basal area of 488 undergrowth trees - here hornbeam and lime - on the species richness and abundance of nearly 489 all the ecological groups. The effects tended to be logically ordered among ecological groups for 490 species richness - with a higher impact for NF groups than for PF (peri-forest) and then AF 491 groups (cf. Table 5) -, but less so for abundance data. Quantifications of these effects had rarely 492 been made. Kwiatkowska et al. (1997) have analyzed the relationship between species richness 493 and density and mean diameter of hornbeam saplings; here, we propose to use the basal area of 494 undergrowth tree species to quantify understory diversity - as Baker and van Lear (1998) did -, a 495 parameter that depends both on density and mean diameter.

496 Other authors (Ewald, 2002, Spyreas and Matthews, 2006, Rogers et al., 2008) have related 497 understory biodiversity to total tree abundance - measured as density, cover, basal area at breast 498 height, volume or biomass -, without any specific reference to the tree species composition. 499 Although different results were found when using tree cover as a measure of tree abundance 500 (Tyler, 1989), these publications generally reported a decrease in understory species richness 501 with increasing abundance. Based on the analysis of different ecological groups, we either found 
such a decline or no trend of diversity with total tree abundance (Tables 5 and 6). These are cases

503 of a decrease in biodiversity that may be due to asymmetric competition by trees on understory

504 plants, more likely to occur in mesic or humid conditions than under dry conditions (Ewald,

505 2002). Although nestedness should be checked at the species level, our results for model

506 (TGI+TA) probably point to a nested structure of communities with respect to basal area (here:

507 TA), as in Spyreas and Matthews (2006), in the sense that the communities had monotonic

508 species richness variations along the TA gradient, with less rich communities being composed of

509 species that were also present in richer communities. Indeed, the ecological groups studied either

510 did not depend on TA or declined in species richness and abundance with TA. In particular, as in

511 Spyreas and Matthews (2006) and Rogers et al. (2008), NF and PF herbaceous species were the

512 most impacted in terms of species richness and there was no sign of enrichment of forest species

513 in high TA stands.

514 It may be useful to discuss these results in terms of successional models of forest vegetation

515 and the associated debate about the "linkage" between forest strata (Spyreas and Matthews, 2006,

516 Gilliam, 2007). The null model of succession as implicitly hypothesized by Spyreas and

517 Matthews (2006) is a model of linkage between forest strata matching the relay floristics

518 successional model sensu Egler (1954), where species frequency optima are placed continuously

519 along the successional or basal area gradient. Here, mature forest species are assumed to be

520 associated with older successional stages or stages with higher basal areas, or to increase in

521 frequency in such contexts. This model fits neither the observations in our study nor in the many

522 studies cited above. Actually, "mesification" -corresponding to an increase in the abundance of

523 the overstory stratum or of undergrowth, mesophanerophytes and associated canopy cover - is a

524 source of degradation rather than recovery, as hypothesized in the above null model (Spyreas and

525 Matthews, 2006). Although for AF species richness our negligibility results are consistent with 
526 Spyreas and Matthews (2006)'s "decoupling between strata” terminology, what we observe for

527 abundance and PF and NF species richness data would be better termed "reversed coupling

528 between strata" - except for AF bryophyte species (cf. line "G.Un" in Tables 5 \& 6). Why is this

529 so? The first possible explanation is simply that the null model of succession is wrong: the true

530 model should be a nested successional model, where "all" the species are equally or more

531 frequent in young, disturbed stands than in old, mesified stands (e.g. Clark et al., 2003, Redburn

532 and Strong, 2008). More precisely, in both natural and artificial conditions, forest species

533 frequency and richness would either decline or remain stable during succession or mesification,

534 with all other species groups declining. The second explanation could be that natural succession

535 and succession under altered conditions are fundamentally different. Altered conditions could

536 include alterations in the disturbance regime, changes in ungulate densities or in the dispersal

537 intensity of forest species due either to their low frequency in the landscape or to fragmentation

538 (Rogers et al., 2008, Spyreas and Matthews, 2006). Natural succession would be close to the

539 relay floristics model under a natural disturbance regime due to the more frequent removal of

540 some forest species by natural disturbances such as fire. Altered succession on the other hand,

541 would be nested as described in the above explanation. However, the relevance of the relay

542 floristics or nested successional models might vary with site type, climatic fluctuations and

543 historical and spatial contingencies (Veblen and Lorenz, 1986, Pickett et al., 2001 and Dovciak et

544 al., 2005).

546 Statistical comments: negligibility and less than Poisson distributions

547 For species richness data, we have used new probability distributions that allow us to account

548 for both under- and over-dispersion relative to the Poisson distribution. As far as we know, this is

549 the first time that such under-dispersed distributions have been used in regression models applied 
550 to ecology. This has allowed us to reach more precise estimates, especially for bryophytes (cf.

551 Gosselin, Submitted b). Indeed, for bryophyte and woody species groups, dispersion parameters 552 were below 1 - indicating under-dispersion relative to the Poisson distribution.

553 Secondly, we have insisted on the interest of using statistical tools - in short equivalence

554 tests - to detect cases where results are judged as biologically negligible from cases where they

555 are not negligible or cases where information is insufficient to judge. This echoes many calls for

556 the estimation of effects rather than the test of null hypotheses from specialists working across

557 the borderline between statistics and ecology (Johnson, 1999, Anderson et al., 2000). The first

558 advantage of equivalence tests is that they introduce a decision category that does not exist in

559 point null hypothesis testing: the case where the estimate is judged negligible. This facilitates a

560 more balanced decision: is there any non-negligible effect or not? A second advantage to the

561 approach is in cases where the real effects are too small to be of biological or managerial

562 relevance. With "insufficient" data, classical point null hypothesis testing may not conclude

563 anything because the null hypothesis will not be rejected and a "need-for-more -data" syndrome

564 may appear. In such situations, equivalence tests will more easily conclude that the effect is truly

565 negligible. In our case, the number of clear decisions for species richness data was greater with

566 equivalence tests than with point null hypothesis testing while it was the same for abundance data

567 (cf. bold and underlined figures in Table 7). However, it is sometimes possible for the point null

568 hypothesis to be rejected even though the effect is judged negligible: this occurred once in our

569 analyses (Table 7). The reverse is logically impossible: an effect cannot be judged non-negligible

570 and non-significant. 
The small extent of the study site and the limited number of replicates are the first obvious

574 limitations in our study. Furthermore, the sampling scheme was neither a random sample from 575 deciduous stands in the region nor a completely controlled stratified sampling. All these elements, together with the levels of variability in the data, meant that many estimators could not be categorized as negligible or non-negligible (Tables $5 \& 6$ ). Yet, for the basal area of undergrowth tree species, the fact that our results strongly echo similar results found in other deciduous forests, where a transition phase seems to be under way (cf. above), gives us some confidence in our results.

Broader-scale studies in terms of number of replicates, extent of region and site variability are desirable, provided they incorporate ecological sources of variation such as site variability

583 into the statistical model. One such study was attempted in Barbier (2007), and gave qualitatively

584 similar results to those of the present study, i.e. TGAS was one of the best models, TGR and

585 TGI+TGD were less effective with globally non-significant coefficients for TGR, and negative

586 effects of shade tolerant trees on biodiversity were observed - except for mature forest 587 herbaceous species.

If such tree abundance models are to be tested in other conditions, researchers should

589 think further on the quantities used for tree abundance and/or on the ecological conditions under

590 which the models should be used. Indeed, as pointed out by Daubenmire and Daubenmire (1968),

591 quantities such as basal area or volume might be less representative of the impact of tree species

592 on light availability than models based on cover. For example, if the sampling plots included an

593 important ratio of senescent trees, there could be a high basal area but a low light interception.

594 The relationship between basal area and light capture might thus vary among DBH classes, or 595 across stand types, or in mixed stands. 
596 Barbier (2007) did not have the opportunity to investigate interactions between tree species

597 composition and site characteristics. Yet, many previous papers point in this direction (Tyler, 598 1989, Michalet et al., 2002, Callaway, 1997, Callaway et al., 2002). This might partly relate to

599 limiting ecological factors that vary with site type conditions (Härdtle et al., 2003). Similarly, 600 relationships between parameters such as tree species richness and understory biodiversity might

601 well depend on the successional status or the range of successional stages studied (Auclair and 602 Goff, 1971, Gilliam et al., 1995). We could not deal with this question due to the limited scope of 603 our sample.

Another obvious limitation of our study - and this is also true for almost all the literature

605 on the subject - is that it was observational and not experimental. An experimental approach used

606 by Kwiatkowska and Wyszomirski (1990) based on the cut of hornbeams has mostly

607 corroborated observational results. This method could be generalized to other tree species or to

608 experimental manipulations through tree cutting of other ecological parameters - e.g. tree genus

609 richness. An alternative would be to use experimental plantations as in Scherer-Lorenzen et al.

610 (2007).

611 In our study, we restricted our analyses to species richness and cover for only certain

612 ecological classifications. Analyses should also be done at the species level and for other

613 ecological groups that are relevant to the ecological questions (e.g. associated with leaf

614 phenology, soil nutrient richness...). Also, analyses of conservation value of biodiversity (Duelli

615 and Obrist, 2003), beta-diversity (Aubert et al., 2004) and evenness could enrich the analysis.

616 Another challenge is to use multivariate models such as the one implying the abundance

617 of various groups of tree species (TGAS) in reports on sustainable forest management. It is

618 indeed difficult to communicate a multivariate model in a report intended for the lay public. An 
619 alternative might be to simulate the associated expected changes in components of biodiversity

620 from the observed temporal changes in tree species abundances based on the statistical models.

621 Our study was also limited in that we considered only one broad taxonomic group, which

622 is not necessarily indicative of other taxonomic groups. Indeed, some other taxonomic groups

623 studied in the same plots - such as carabid beetles - did not show the same trends, either in terms

624 of the best models or the direction of the effects (results not shown).

625 Finally and more generally, this paper has taken for granted that biodiversity could be 626 accounted for chiefly with pressure-type indicators. Yet, this may not necessarily be the case

627 since biodiversity states and variations are the result of the cumulative effects of different

628 pressures. We therefore support the idea that biodiversity components should be directly

629 monitored in sustainable forest management policy assessment. Yet, pressure level indicators or

630 analyses of this type do offer the possibility to better interpret observed trends, and possibly to

631 extrapolate to situations where only dendrometric and no biodiversity information is available.

632

\section{Conclusions}

634 Our paper promotes testing biodiversity indicators based on parametric statistical models

635 which are - to our knowledge - the only ones that allow the use of both model comparison

636 techniques and the study of negligible effects. In particular, methods based simply on correlation

637 coefficients and associated probabilities of significance are to our knowledge incapable of

638 distinguishing the different situations of non-negligible trend as defined by Dixon and Pechmann

639 (2005). Based on our results and on this discussion, we believe that for these oak-dominated

640 types of forests with a potentially strong hornbeam component but without beech, TGAS models

641 - and maybe even a simpler model with only the basal area of undergrowth trees - are better than 
models based on tree genus diversity. The generalization of these results to broader sampling

643 sites with more variable site conditions and tree species composition is desirable.

\section{Acknowledgements}

646 We are thankful to Yann Dumas, Marc Roussel and Vincent Laquierre for dendrometric 647 measurements and to Vicki Moore for correcting the English. We are also grateful to the 648 organizers of the IUFRO Conference in Kamloops for the great job they did, and to three 649 anonymous reviewers whose comments were very useful. We would also like to acknowledge 650 Jean-Claude Rameau, who was originally part of S.B. PhD project and left us too soon. This 651 work was partly funded by the Research Program "Biodiversité et Gestion Forestière" (BGF) of 652 the French Ministry of Environment through the GIP Ecofor (convention ECOFOR $\mathbf{N}^{\circ} 1998-11$ ) 653 and by the French Administrative Region "Centre".

\section{References}

656 anonymous, 1999. Qualité des sols. AFNOR, Paris.

657 Anderson, D.R., Burnham, K.P., Thompson, W.L., 2000. Null hypothesis testing: Problems, 658 prevalence, and an alternative. Journal of Wildlife Management 64, 912-923.

659 Aubert, M., Bureau, F., Alard, D., Bardat, J., 2004. Effect of tree mixture on the humic epipedon 660 and vegetation diversity in managed beech forests (Normandy, France). Canadian Journal of 661 Forest Research 34, 233-248.

662 Auclair, A.N., Goff, F.G., 1971. Diversity relations of upland forests in the western Great Lakes 663 area. The American Naturalist 105, 499-528.

664 Baker, T.T., van Lear, D.H., 1998. Relations between density of rhododendron thickets and 665 diversity of riparian forests. Forest Ecology and Management 109, 21-32. 
666 Barbier, S., Balandier, P., Gosselin, F., Influence of several tree traits on rainfall partitioning in 667 temperate and boreal forests: a review. Annals of Forest Science In Press.

668 Barbier, S., Gosselin, F., Balandier, P., 2008. Influence of tree species on understory vegetation 669 diversity and mechanisms involved - a critical review for temperate and boreal forests. Forest 670 Ecology and Management 254, 1-15.

671 Barbier, S., 2007. Influence de la diversité, de la composition et de l'abondance des essences 672 forestières sur la diversité floristique des forêts tempérées. Université d'Orléans, Orléans, 673 http://tel.archives-ouvertes.fr/tel-00238532/fr.

674 Betts, M.G., Diamond, A.W., Forbes, G.J., Frego, K.A., Loo, J.A., Matson, B., Roberts, M.R., 675 Villard, M.A., Wissink, R., Wuest, L., 2005. Plantations and biodiversity: A comment on the 676 debate in New Brunswick. The Forestry Chronicle 81, 265-269.

677 Brêthes, A., Brun, J.J., Jabiol, B., Ponge, J., Toutain, F., 1995. Classification of forest humus 678 forms: A French proposal. Annals of Forest Science 52, 535-546.

679 Brewer, R., 1980. A half-century of changes in the herb layer of a climax deciduous forest in 680 Michigan. Journal of Ecology 68, 823-832.

681 Callaway, R.M., Brooker, R.W., Choler, P., Kikvidze, Z., Lortie, C.J., Michalet, R., Paolini, L., 682 Pugnaire, F.I., Newingham, B., Aschehoug, E.T., Armas, C., Kikodze, D., Cook, B.J., 2002.

683 Positive interactions among alpine plants increase with stress. Nature 417, 844-848.

684 Callaway, R.M., 1997. Positive interactions in plant communities and the individualistic685 continuum concept. Oecologia 112, 143-149.

686 Camp, R.J., Seavy, N.E., Gorresen, P.M., Reynolds, M.H., 2008. A statistical test to show 687 negligible trend: Comment. Ecology 89, 1469-1472.

688 Chamberlin, T., 1965. The method of multiple working hypotheses. Science 148, 754-759. 
689 Clark, D.F., Antos, J.A., Bradfield, G.E., 2003. Succession in sub-boreal forests of West-Central

690 British Columbia. Journal of Vegetation Science 14, 721-732.

691 Corley, M.F.V., Crundwell, A.C., Dull, R., Hill, M.O., Smith, A.J.E., 1981. Mosses of Europe

692 and the Azores ; an annotated list of species, with synonyms from the recent literature. Journal of

693 Bryology 11, 609-689.

694 Corley, M.F.V., Crundwell, A.C., 1991. Additions and amendments to the mosses of Europe and 695 the Azores. Journal of Bryology 16, 337-356.

696 Daubenmire, R., Daubenmire, J.B., 1968. Forest vegetation of eastern Washington and northern

697 Idaho. Technical Bulletin, Washington Agricultural Experiment Station, Pullman 60, 104.

698 Dixon, P.M., Pechmann, J.H.K., 2005. A statistical test to show negligible trend. Ecology 86,

$699 \quad 1751-1756$.

700 Dovciak, M., Frelich, L.E., Reich, P.B., 2005. Pathways in old-field succession to white pine:

701 Seed rain, shade, and climate effects. Ecological Monographs 75, 363-378.

702 Duelli, P., Obrist, M.K., 2003. Regional biodiversity in an agricultural landscape: the

703 contribution of seminatural habitat islands. Basic and Applied Ecology 4, 129-138.

704 Egler, F.E., 1954. Vegetation Science Concepts I. Initial floristic composition, a factor in old-

705 field vegetation development. Vegetatio 4, 412-417.

706 Ellenberg, H., Weber, H.E., Düll, R., Wirth, V., Werner, W., Paulißen, D., 1992. Zeigerwerte von

707 Pflanzen in Mitteleuropa. Verlag Goltze, Göttingen.

708 Evstigneev, O.I., 1988. Developmental features of broadleaved trees under the forest canopy in

709 various light conditions. Botanicheskii Zhurnal (st. Petersburg) 73, 1730-1736.

710 Ewald, J., 2002. Multiple controls of understorey plant richness in mountain forests of the

711 Bavarian Alps. Phytocoenologia 32, 85-100. 
712 Gelman, A., Carlin, J.B., Stern, H.S., Rubin, D.B., 2004. Bayesian Data Analysis. Chapman \& 713 Hall, Boca Raton.

714 Gilliam, F.S., Turrill, N.L., Adams, M.B., 1995. Herbaceous-layer and overstory species in clear-

715 cut and mature central Appalachian hardwood forests. Ecological Applications 5, 947-955.

716 Gilliam, F.S., 2007. The ecological significance of the herbaceous layer in temperate forest

717 ecosystems. BioScience 57, 845-858.

718 Gleason, H.A., 1926. The individualistic concept of the plant association. Bulletin of the Torrey

719 Botanical Club 543, 7-26.

720 Glenn-Lewin, D.C., 1977. Species diversity in North American temperate forests. Vegetatio 33,

$721 \quad 153-162$.

722 Gosselin, F., Gosselin, M., 2004. Analyser les variations de biodiversité : outils et méthodes. In:

723 Gosselin M., Larroussinie O. (Eds.), Biodiversité et gestion forestière : connaître pour préserver -

724 synthèse bibliographique. Coédition GIP Ecofor - Cemagref Editions, Antony, pp. 58-99.

725 Grolle, R., 1983. Hepatics of Europe including the Azores : an annotated list of species, with 726 synonyms from the recent literature. Journal of Bryology 12, 403-459.

727 Härdtle, W., von Oheimb, G., Westphal, C., 2003. The effects of light and soil conditions on the 728 species richness of the ground vegetation of deciduous forests in northern Germany (Schleswig729 Holstein). Forest Ecology and Management 182, 327-338.

730 Hilborn, R., Mangel, M., 1997. The ecological detective: confronting models with data. Princeton 731 University Press, Princeton (NJ).

732 Hodgson, J.G., Grime, J.P., Hunt, R., Thompson, K., 1995. The electronic comparative plant 733 ecology. Chapman \& Hall, London. 
734 Jabiol, B., Höltermann, A., Gégout, J.C., Ponge, J.F., Brêthes, A., 2000. Typologie des formes

735 d'humus peu actives. Validation par des critères macro- et micromorphologiques, biologiques et

736 chimiques. Etude et Gestion des Sols 7, 133-154.

737 Johnson, D.H., 1999. The insignificance of statistical significance testing. Journal of Wildlife

738 Management 63, 763-772.

739 Johnson, V.E., 2007. Bayesian Model Assessment Using Pivotal Quantities. Bayesian Analysis 2, $740 \quad 719-734$.

741 Julve, P., 2002. Index écologique et chorologique de la flore de France,

742 http://perso.wanadoo.fr/philippe.julve/catminat.htm\#INDEXFLORE .

743 Kerguélen, M., 1999. Index synonymique de la flore de France, http://www2.dijon.inra.fr/flore-

744 france/.

745 Korb, J.E., Daniels, M.L., Laughlin, D.C., Fulé, P.Z., 2007. Understory communities of warm-

746 dry, mixed-conifer forests in southwestern Colorado. Southwestern Naturalist 52, 493-503.

747 Kwiatkowska, A.J., Spalik, K., Michalak, E., Palinska, A., Panufnik, D., 1997. Influence of the 748 size and density of Carpinus betulus on the spatial distribution and rate of deletion of forest-floor 749 species in thermophilous oak forest. Plant Ecology 129, 1-10.

750 Kwiatkowska, A.J., Wyszomirski, T., 1990. Species deletion in Potentillo albae-Quercetum

751 phytocoenoses reversed by the removal of Carpinus betulus. Vegetatio 87, 115-126.

752 Kwiatkowska, A.J., 1994. Changes in the species richness, spatial pattern and species frequency 753 associated with the decline of oak forest. Vegetatio 112, 171-180.

754 Lindenmayer, D.B., Margules, C.R., Botkin, D.B., 2000. Indicators of biodiversity for 755 ecologically sustainable forest management. Conservation Biology 14, 941-950. 
756 Lindenmayer, D.B., 1999. Future directions for biodiversity conservation in managed forests :

757 indicator species, impact studies and monitoring programs. Forest Ecology and Management 115, $758 \quad 277-287$.

759 Liu, I., Agresti, A., 2005. The analysis of ordered categorical data: An overview and a survey of 760 recent developments. Test 14, 1-73.

761 MCPFE, 2003. Improved pan-European indicators for sustainable forest management as adopted 762 by the MCPFE Expert Level Meeting. Ministerial Conference on the Protection of Forests in 763 Europe, Vienna.

764 Météo France, 1996. Normales climatiques. Période 1961 - 1990. Tome 1. Stations de Métropole. 765 Météo France, Paris, France.

766 Michalet, R., Rolland, C., Joud, D., Gafta, D., Callaway, R.M., 2002. Associations between 767 canopy and understory species increase along a rainshadow gradient in the Alps: Habitat 768 heterogeneity or facilitation? Plant Ecology 165, 145-160.

769 Ministère de l'Agriculture et de la Pêche, 2006. Les indicateurs de gestion durable des forêts 770 françaises - Edition 2005. MAP, Paris.

771 Mölder, A., Bernhardt-Römermann, M., Schmidt, W., 2008. Herb-layer diversity in deciduous 772 forests: Raised by tree richness or beaten by beech? Forest Ecology and Management 256, 272773281.

774 Pickett, S.T., Cadenasso, M.L., Bartha, S., 2001. Implications from the Buell-Small Succession 775 Study for vegetation restoration. Applied Vegetation Science 4, 41-52.

776 Ponge, J.F., Chevalier, R., Loussot, P., 2002. Humus index: an integrated tool for the assessment 777 of forest floor and topsoil properties. Soil Science Society of America Journal 66, 1996-2001. 
778 Rameau, J.C., Mansion, D., Dumé, G., Timbal, J., Lecointe, A., Dupont, P., Keller, R., 1989.

779 Flore forestière française. Guide écologique illustré. Tome 1 : Plaines et collines. Institut pour le 780 Développement Forestier, Paris.

781 Redburn, M.J., Strong, W.L., 2008. Successional development of silviculturally treated and 782 untreated high-latitude Populus tremuloides clearcuts in northern Alberta, Canada. Forest 783 Ecology and Management 255, 2937-2949.

784 Rice, J., Anderson, B.W., Ohmart, R.D., 1984. Comparison of the importance of different habitat 785 attributes to avian community organization. Journal of Wildlife Management 48, 895-911.

786 Roberts, G.O., Rosenthal, J.S., Examples of adaptive MCMC. Journal of Computational and 787 Graphical Statistics In Press.

788 Rogers, D.A., Rooney, T.P., Olson, D., Waller, D.M., 2008. Shifts in Southern Wisconsin forest 789 canopy and understory richness, composition, and heterogeneity. Ecology 89, 2482-2492.

790 Scherer-Lorenzen, M., Schulze, E.D., Don, A., Schumacher, J., Weller, E., 2007. Exploring the 791 functional significance of forest diversity: A new long-term experiment with temperate tree 792 species (BIOTREE). Perspectives in Plant Ecology, Evolution and Systematics 9, 53-70.

793 Sonohat, G., Balandier, P., Ruchaud, F., 2004. Predicting solar radiation transmittance in the 794 understory of even-aged coniferous stands in temperate forests. Annals of Forest Science 61, 629795641.

796 Spiegelhalter, D., Best, N., Carlin, J.B., van der Linde, A., 2002. Bayesian measures of model 797 complexity and fit (with Discussion). Journal of the Royal Statistical Society, Series B 64, 583798616.

799 Spies, T.A., 1997. Forest stand structure, composition, and function. In: Kohn K.A., Franklin J.F. 800 (Eds.), Creating a forestry for the 21 st century - The science of ecosystem management. Island 801 Press, Washington D.C., pp. 11-30. 
802 Spyreas, G., Matthews, J.W., 2006. Floristic conservation value, nested understory floras, and the 803 development of second-growth forest. Ecological Applications 16, 1351-1366.

804 Tyler, G., 1989. Interacting effects of soil acidity and canopy cover on the species composition of 805 field-layer vegetation in oak/hornbeam forests. Forest Ecology and Management 28, 101-114.

806 van der Maarel, E., 1979. Transformation of cover-abundance values in phytosociology and its 807 effects on community similarity. Vegetatio $39,97-144$.

808 Van Oijen, D., Feijen, M., Hommel, P., Den Ouden, J., De Wall, R., 2005. Effects of tree species 809 composition on within-forest distribution of understory species. Applied Vegetation Science 8, $810 \quad 155-166$.

811 Veblen, T.T., Lorenz, D.C., 1986. Anthropogenic disturbance and recovery patterns in montane 812 forests, Colorado Front Range. Physical Geography 7, 1-24.

813 Vera, F.W.M., 2000. Grazing Ecology and Forest History. CABI Publishing, New York.

814 Whittaker, R.H., 1956. Vegetation of the Great Smoky Mountains. Ecological Monographs 6, 181580. 

height). SD is standard deviation.

820

\begin{tabular}{|c|c|c|c|c|}
\hline Ecological & Definition and units & Mean & SD & Range \\
\hline Date & Number of days (from the $1^{\text {st }}$ June 1999 ) & 11.3 & 14.4 & $-15-55$ \\
\hline G & Total BA $\left(\mathrm{m}^{2} \cdot \mathrm{ha}^{-1}\right)$ & 29.6 & 6.9 & $13.9-44.0$ \\
\hline G.Pi & BA of "Pioneer trees" (Betula sp. and Populus sp.) $\left(\mathrm{m}^{2} . \mathrm{ha}^{-1}\right)$ & 4.9 & 5.9 & $0.0-21.9$ \\
\hline G.Qu & $\begin{array}{l}\text { BA of "Oaks" or post-pioneer tree genera (Quercus petraea } \\
\text { and } Q . \text { robur; also including tree genera not in G.Pi and G.Un) } \\
\left(\mathrm{m}^{2} \cdot \mathrm{ha}^{-1}\right)\end{array}$ & 14.6 & 7.8 & $0.6-30.5$ \\
\hline G.Un & $\begin{array}{l}\text { BA of "undergrowth" tree genera (Carpinus betulus and Tilia } \\
s p .)\left(\mathrm{m}^{2} \cdot \mathrm{ha}^{-1}\right)\end{array}$ & 10.12 & 8.4 & $0.0-32.2$ \\
\hline TGR & $\begin{array}{l}\text { Tree genus richness in the dendrometric relevé (varying radius } \\
\text { sampling, up to } 1520 \mathrm{~m}^{2} \text { ) (\# of species) }\end{array}$ & 4.6 & 1.5 & $1-8$ \\
\hline
\end{tabular}




\begin{tabular}{|c|c|c|c|c|}
\hline TGD & Tree genus dominance: calculated as $\max ($ G.Pi,G.Qu,G.Un)/G & 0.6 & 0.2 & $0.3-1.0$ \\
\hline pH.KCl.A & $\mathrm{pH} \mathrm{KCl}$ of the organic-mineral layer of the soil $(5-10 \mathrm{~cm}$ deep) & 3.8 & 0.3 & $3.2-4.7$ \\
\hline pH.KCl.B & $\mathrm{pH} \mathrm{KCl}$ of the first mineral layer of the soil $(15-25 \mathrm{~cm}$ deep $)$ & 3.7 & 0.1 & $3.6-3.9$ \\
\hline C/N.A & $\begin{array}{l}\text { Ratio of organic } \mathrm{C} \text { over total Nitrogen in the organic-mineral } \\
\text { layer }\end{array}$ & 16.6 & 1.0 & $14.0-19.0$ \\
\hline HUMUS & Humus index (cf. text) & 5.1 & 1.3 & $2.0-6.2$ \\
\hline ClayDepth & Depth in the soil at which clay was dominant $(\mathrm{cm})$ & 45.6 & 4.7 & $31.2-57.5$ \\
\hline
\end{tabular}


821 Table 2. Definition of the specific parameters identifying the ecological models (cf. Table 1

822 for the definition of variables).

\begin{tabular}{ll}
\hline Model & Ecological parameters specific to the model (not including the intercept) \\
acronym & $\sim$ TGI \\
& Tree genus identity of the group which has the highest $\mathrm{G}$ in the plot, among Pi, \\
& Qu or Un as defined for TGAS \\
& $\sim \mathrm{G}$
\end{tabular}

$T G I+T A \quad \sim \mathrm{TGI}+\mathrm{G}$

Addition of the TGI and G effects- with no interaction

TGAS G.Pi+G.Qu+G.Un

\begin{tabular}{ll}
\hline TGI+TGD & $\sim$ TGI+TGD \\
\hline TGR & $\sim$ TGR \\
\hline mTGR4 & $\sim \min (\mathrm{TGR}, 4)$ \\
& Minimum between TGR and 4 \\
& $\sim$ Date \\
\hline Date & $\sim$ Identity of the forest Block (two levels: between Southern Block and Northern \\
& Block) \\
\hline Soil & $\sim$ pH.KCl.A+C/N.A+HUMUS+ClayDepth \\
\hline null & 0
\end{tabular}


823 Table 3. Differences in DIC (Deviance Information Criterion) values between the different

824 ecological models and the null model, for species richness data for the ecological groups by

825 successional classification (SUCC): "AF" for mature forest, "PF" for peri-forest and "NF" for

826 non-forest species. The smaller the DIC, the better the model with respect to the others. Within

827 each ecological group, the model with the smallest DIC was underlined and the DIC values

828 within 5 units to this model were put in bold. For each line, the column "Sum" gives the (sum of)

829 DIC differences over ecological groups.

830

\begin{tabular}{|c|c|c|c|c|c|c|c|}
\hline \multicolumn{8}{|l|}{ Model } \\
\hline \multirow[t]{2}{*}{ Acronym } & \multirow{2}{*}{$\begin{array}{c}\text { Bryophytes } \\
\text { AF }\end{array}$} & \multicolumn{3}{|c|}{ Herbaceous } & \multicolumn{2}{|c|}{ Woody } & \multirow[t]{2}{*}{ Sum } \\
\hline & & $\mathrm{AF}$ & $\mathrm{PF}$ & $\mathrm{NF}$ & $\mathrm{AF}$ & $\mathrm{PF}$ & \\
\hline TGI & -3.4 & -12.8 & -4.9 & -12.4 & -4.7 & -6.5 & -44.7 \\
\hline TA & -2.8 & -5.5 & -11.5 & -17.4 & -2.2 & -19.7 & -59.0 \\
\hline TGI+TA & -3.9 & -14.3 & -13.9 & -23.1 & -4.8 & -21.9 & -82.0 \\
\hline TGAS & -4.9 & -21.0 & -18.2 & $\underline{-35.7}$ & -9.1 & -32.6 & -121.4 \\
\hline TGI+TGD & -3.1 & -15.2 & -6.5 & -16.5 & -4.7 & -8.7 & -54.8 \\
\hline TGR & -1.4 & 0.0 & 0.0 & 0.0 & -1.5 & 0.0 & -2.7 \\
\hline mTGR4 & -0.3 & -0.6 & -0.0 & -1.2 & -0.2 & -2.5 & -4.8 \\
\hline Date & 0.2 & -2.6 & -0.9 & -0.8 & -0.5 & -0.1 & -4.7 \\
\hline Block & -6.1 & 0.0 & -0.6 & -0.5 & -0.4 & -1.8 & -9.3 \\
\hline Soil & -19.5 & -3.9 & -9.0 & -13.9 & -8.9 & -12.7 & -68.0 \\
\hline null & 0 & 0 & 0 & 0 & 0 & 0 & 0 \\
\hline
\end{tabular}


832 Table 4. Differences in DIC (Deviance Information Criterion) values between the different

833 ecological models and the null model, for abundance data for the ecological groups by

834 successional classification (SUCC). The rest of the legend is the same as in Table 3.

835

\begin{tabular}{|c|c|c|c|c|c|c|c|}
\hline \multirow[t]{2}{*}{ Model Acronym } & \multirow{2}{*}{$\begin{array}{c}\text { Bryophytes } \\
\text { AF }\end{array}$} & \multicolumn{3}{|c|}{ Herbaceous } & \multicolumn{2}{|c|}{ Woody } & \multirow[t]{2}{*}{ Sum } \\
\hline & & $\mathrm{AF}$ & $\mathrm{PF}$ & $\mathrm{NF}$ & $\mathrm{AF}$ & $\mathrm{PF}$ & \\
\hline TGI & -10.1 & -8.8 & -9.4 & -7.9 & -13.8 & -6.6 & -56.6 \\
\hline TA & -5.3 & -5.5 & -17.6 & -21.4 & -26.6 & -10.4 & -86.8 \\
\hline TGI+TA & -12.5 & -10.1 & -23.0 & -23.8 & -30.7 & -15.6 & -115.7 \\
\hline TGAS & $\underline{-14.9}$ & -9.0 & $\underline{-26.4}$ & $\underline{-29.4}$ & $\underline{-33.9}$ & $\underline{-21.2}$ & $\underline{-134.8}$ \\
\hline TGI+TGD & -11.8 & -9.1 & -15.6 & -22.3 & -22.5 & -7.4 & -88.7 \\
\hline TGR & -0.1 & -0.2 & 0.1 & -0.7 & -0.6 & -0.3 & -1.8 \\
\hline mTGR4 & -1.2 & -0.1 & -1.1 & -6.8 & -8.5 & -0.5 & -18.2 \\
\hline Date & -1.1 & -4.4 & -0.4 & -0.8 & -0.0 & -2.0 & -8.7 \\
\hline Block & -0.9 & -2.1 & -1.4 & -0.7 & -1.1 & 0.1 & -6.1 \\
\hline Soil & -12.9 & $\underline{-10.9}$ & -8.9 & -11.4 & -16.2 & -5.9 & -66.2 \\
\hline null & 0 & 0 & 0 & 0 & 0 & 0 & 0 \\
\hline
\end{tabular}

836 
838 Table 5. Analysis of the multiplicative effect of a given variation of selected ecological

839 parameters on the species richness of the ecological groups by successional classification

840 (SUCC). Variations were an addition of $5 \mathrm{~m}^{2} \cdot \mathrm{ha}^{-1}$ for basal area data (G.Pi, G.Qu, G.Un, G), of

$841 \quad 1.5$ genera for TGR and mTGR4 and of 0.2 for TGD (Tree Genus Dominance). Levels of

842 statistical significance of parameters are symbolized as follows: $* * *=p<0.001, * *=p<0.01, *=$ $843 \mathrm{p}<0.05$. "0" and "00" indicate that the effect has a P-value of at least 0.95 of being negligible, at 844 two different levels (cf. text). "-" and "--" indicate that the effect has a P-value of at least 0.95 of 845 being negative and non-negligible, at two different levels (cf. text). The rest of the legend is the 846 same as in Table 3. 


\begin{tabular}{|c|c|c|c|c|c|c|}
\hline \multicolumn{7}{|l|}{ Model } \\
\hline \multirow[t]{2}{*}{ Acronym } & \multicolumn{2}{|l|}{ Bryophytes } & \multicolumn{2}{|l|}{ Herbaceous } & \multicolumn{2}{|c|}{ Woody } \\
\hline & $\mathrm{AF}$ & $\mathrm{AF}$ & $\mathrm{PF}$ & $\mathrm{NF}$ & $\mathrm{AF}$ & $\mathrm{PF}$ \\
\hline & $1.01^{00}$ & 1.18 & 0.96 & 0.97 & $1.05^{0}$ & $0.98^{0}$ \\
\hline \multirow[t]{2}{*}{ G.Pi } & {$[0.94 ; 1.08]$} & {$[1.00 ; 1.38]$} & {$[0.67 ; 1.37]$} & {$[0.63 ; 1.41]$} & {$[0.92 ; 1.21]$} & [0.88;1.09] \\
\hline & $0.99^{00}$ & $1.06^{0}$ & 0.85 & 0.81 & $1.06^{0}$ & $0.89^{*}, 0$ \\
\hline \multirow[t]{2}{*}{$\mathrm{G} . \mathrm{Qu}$} & {$[0.93 ; 1.06]$} & {$[0.91 ; 1.22]$} & {$[0.62 ; 1.14]$} & {$[0.58 ; 1.08]$} & {$[0.93 ; 1.20]$} & {$[0.81 ; 0.98]$} \\
\hline & $1.03^{00}$ & $0.83^{* *}$ & $0.62^{* * *,--}$ & $0.40^{* * *,--}$ & $0.93^{0}$ & $0.80^{* * *,-}$ \\
\hline \multirow[t]{2}{*}{ G.Un } & {$[0.99 ; 1.07]$} & {$[0.75 ; 0.92]$} & {$[0.48 ; 0.79]$} & {$[0.29 ; 0.53]$} & {$[0.85 ; 1.01]$} & {$[0.75 ; 0.85]$} \\
\hline & $1.02^{00}$ & $0.93^{0}$ & $0.67^{* *,-}$ & $0.57^{* *,--}$ & $0.98^{0}$ & $0.84^{* * * *,-}$ \\
\hline \multirow[t]{2}{*}{$\mathrm{G}$ in TGI+TA } & [0.97;1.07] & {$[0.83 ; 1.04]$} & {$[0.50 ; 0.88]$} & {$[0.40 ; 0.81]$} & {$[0.89 ; 1.08]$} & {$[0.78 ; 0.92]$} \\
\hline & $0.97^{00}$ & $1.01^{0}$ & 1.02 & 0.98 & $1.07^{0}$ & $1.00^{\circ}$ \\
\hline \multirow[t]{2}{*}{ TGR } & {$[0.91 ; 1.03]$} & {$[0.87 ; 1.17]$} & {$[0.73 ; 1.41]$} & {$[0.65 ; 1.45]$} & {$[0.96 ; 1.19]$} & {$[0.90 ; 1.14]$} \\
\hline & $0.97^{0}$ & 0.90 & 0.91 & 0.57 & 1.02 & 0.84 \\
\hline mTGR4 & {$[0.86 ; 1.08]$} & {$[0.68 ; 1.19]$} & {$[0.42 ; 1.75]$} & {$[0.19 ; 1.40]$} & {$[0.82 ; 1.31]$} & {$[0.67 ; 1.05]$} \\
\hline TGD in & $1.00^{00}$ & 1.14 & 1.24 & 1.55 & $0.99^{0}$ & 1.11 \\
\hline TGI+TGD & {$[0.94 ; 1.07]$} & {$[0.96 ; 1.36]$} & {$[0.86 ; 1.79]$} & {$[0.98 ; 2.53]$} & {$[0.87 ; 1.13]$} & {$[0.96 ; 1.27]$} \\
\hline
\end{tabular}


848 Table 6. Analysis of the multiplicative effect of a given variation of selected ecological

849 parameters on the odds value of the cumulative probabilities $P\left(Y>\alpha_{i}\right)$ for abundance data of the

850 ecological groups by successional classification (SUCC). Variations were an addition of $5 \mathrm{~m}^{2} . \mathrm{ha}^{-1}$

851 for basal area data (G.Pi, G.Qu, G.Un, G), of 1.5 genera for TGR and mTGR4 and of 0.2 for

852 TGD (Tree genus Dominance). The rest of the notation is as in Table 5.

\section{Model}

Acronym

Bryophytes

Herbaceous

Woody

\begin{tabular}{cccccc}
\hline AF & AF & PF & NF & AF & PF \\
\hline 1.90 & 1.01 & 0.92 & 0.82 & 0.49 & 1.15
\end{tabular}

G.Pi

$[0.92 ; 3.93][0.46 ; 2.21][0.47 ; 1.81][0.36 ; 1.86] \quad[0.24 ; 1.00] \quad[0.51 ; 2.54]$

$\begin{array}{llllll}0.96 & 0.69 & 0.68 & 0.61 & 0.54 & 0.53\end{array}$

G.Qu

$[0.53 ; 1.75][0.34 ; 1.37][0.38 ; 1.22][0.31 ; 1.21] \quad[0.27 ; 1.05] \quad[0.24 ; 1.10]$

\begin{tabular}{ccccccc}
\hline & $1.14^{0}$ & $0.48^{* *},-$ & $0.31^{* * *,--}$ & $0.23^{* * *,--}$ & $0.31^{* * *,--}$ & $0.35^{* * *,--}$ \\
G.Un & {$[0.74 ; 1.74]$} & {$[0.30 ; 0.75]$} & {$[0.20 ; 0.49]$} & {$[0.13 ; 0.40]$} & {$[0.20 ; 0.49]$} & {$[0.22 ; 0.56]$} \\
\hline & 1.09 & 0.69 & $0.40^{* * *,---}$ & $0.30^{* * *,--}$ & $0.36^{* * *,--}$ & $0.41^{* * *,--}$
\end{tabular}

$\mathrm{G}$ in TGI+TA $\quad[0.68 ; 1.76][0.40 ; 1.13][0.24 ; 0.63][0.17 ; 0.52] \quad[0.21 ; 0.60] \quad[0.24 ; 0.71]$

$\begin{array}{llllll}1.08^{0} & 0.98 & 1.01 & 0.74 & 0.77 & 1.18\end{array}$

TGR $\quad[0.66 ; 1.75][0.58 ; 1.67][0.59 ; 1.74][0.39 ; 1.38] \quad[0.43 ; 1.38] \quad[0.67 ; 2.12]$

$\begin{array}{llllll}1.41 & 0.88 & 0.56 & 0.19^{* *,--} & 0.14^{* *,--} & 0.57\end{array}$

mTGR4 $\quad[0.51 ; 3.75][0.29 ; 2.67][0.19 ; 1.66][0.05 ; 0.61][0.03 ; 0.50] \quad[0.18 ; 1.75]$

$\begin{array}{lcccccc}\text { TGD in } & 0.78 & 0.50 & 10.1^{* *,++} & 60.8^{* * *,++} & 13.23^{* *,++} & 2.73 \\ \text { TGI+TGD } & {[0.14 ; 3.87]} & {[0.09 ; 2.97]} & {[1.80 ; 53]} & {[8.0 ; 486]} & {[2.28 ; 82]} & {[0.43 ; 17]}\end{array}$


853 Table 7. Synthesis of the correspondences between classical statistical significance - based on the 854 rejection of classical point null hypotheses $(\mathrm{p}=0.05)$ - and equivalence and inequivalence tests 855 giving results about the weak negligibility, non weak negligibility or lack of information about 856 the negligibility of the effects. Each cell contains the number of cases met in Tables 5 and 6 , for 857 Species Richness (in sub-column SR) and Abundance data (in sub-column A). Grey cells 858 correspond to cases that are impossible.

859

\begin{tabular}{|c|c|c|c|c|c|c|}
\hline & \multicolumn{2}{|c|}{ Non significant effect } & \multicolumn{2}{|c|}{ Significant effect } & \multicolumn{2}{|c|}{ Total count } \\
\hline & SR & $\mathrm{A}$ & SR & $\mathrm{A}$ & SR & A \\
\hline $\begin{array}{l}\text { Negligible } \\
\text { effect }\end{array}$ & 18 & 2 & 1 & 0 & $\underline{19}$ & $\underline{\mathbf{2}}$ \\
\hline $\begin{array}{l}\text { Non negligible } \\
\text { effect }\end{array}$ & 0 & 0 & 6 & 14 & $\underline{6}$ & $\underline{14}$ \\
\hline $\begin{array}{l}\text { Without } \\
\text { information }\end{array}$ & 16 & 26 & 1 & 0 & 17 & 26 \\
\hline Total count & 34 & 28 & $\underline{8}$ & $\underline{14}$ & 42 & 42 \\
\hline
\end{tabular}

860

861 